\title{
On the Content of Intercultural Communication Teaching
}

\author{
Lijuan LI
}

School of Foreign Languages, Yibin University, Yibin 644000, Sichuan, China

Keywords: Intercultural Communication, Content, Teaching

\begin{abstract}
The realities in intercultural communication teaching are that students still have no motivation and courage to communicate with the one with different cultural background and that the strangeness and distance between different cultural communicators are still unconquerable. With the development of world's economy and society and the convenience of various kinds of transportation, the world has become a real-life "world village", which generates new challenges for teachers to conduct the intercultural communication teaching in various kinds of ways, mostly in the contents. Intercultural communication courses aiming at improving students' cross-cultural communicative competence should be instructive, pragmatic and applicable, on the basis of which the author tempts to analyze what should be taught in intercultural communication teaching from the perspective of the teachers' role and the students' need.
\end{abstract}

With the development of world's economy and society and the convenience of various kinds of transportation, the world has become a real-life "world village" rather than the one only appearing in books or minds, in response to which, intercultural communication teaching and the relevant courses are of great significance for students to learn and understand the similarities and differences among different cultures; and are helpful for students to play their part in the innovation and advancement of the society at an international level. Based on the teaching experiences of the past years in intercultural communication courses, the author finds many of the content in the referred course books are not attractive to students, which lead to students' disinterest in the study of intercultural communication, not to mention the research and command of them. Although some devoted and diligent learners have a splendid command of the knowledge of cross-cultural communication, they find it very hard to take the knowledge into practice and still feel strong sense of disappointment and depression because of the barriers and obstacles in cultural exchanges. The realities for the students are that they still have no motivation and courage to communicate with the one with different cultural backgrounds and that the strangeness and distance between different cultural communicators are still unconquerable. Intercultural communication courses aiming at improving students' cross-cultural communicative competence should be instructive, pragmatic and applicable, on the basis of which the author tempts to analyze what should be taught in intercultural communication teaching from the perspective of the teachers' role and the students' need.

\section{Teachers' role}

As an instructor of the course, the teacher himself or herself is supposed to be an intercultural communicator with specialized knowledge and skills, including fluent usage of world language or target language, understanding the basic concept and theory of intercultural communication, cherishing a global mentality and clarifying their specific cultural identity and cultural adaptation stage. Many other aspects of a teacher's knowledge and skills of intercultural communication are significant, but the above mentioned are fundamental.

\section{A. Fluent usage of world language or target language}

By speaking of the idea of language, the author means the verbal language. The substance of intercultural communication is in the course of cultural exchanges, while the means to that is in language. We use language to relate to the past, form images of the future and communicate with the outside world. During the process of cross-cultural communication the increasingly close connection between language and culture is unfolded. The diversity of language, a reflection of the environment and values, helps people not only to understand thoroughly the social reality but also 
to express their own special culture values. As Ezra Pound says, "The sum of human wisdom is not contained in any one language, and no single language is capable of expressing all forms and degrees of human comprehension." That demonstrates how come we sometimes find it hard and almost impossible to replace a word in a language with the corresponding word in another language. The relation between word and meaning is arbitrary, and the meaning comes out of context, for which the way it constructs a language is different in various cultures. In the Sapir-Whorf hypothesis it holds that the structure of a language affects the perceptions of reality of its speakers and thus influences their thought patterns and worldviews. People using different languages represent different approaches of encoding and storing ideas, different patterns of conception and consequently different worldviews, customs and cultural backgrounds. The first step for a teacher to understand and master intercultural communication is to command a fluent usage of the world language or the target foreign language, especially its idioms and slangs, and his or her ability to use words bilingually is indeed a remarkable gift.

\section{B. Concept and theory of intercultural communication}

For the questions of "what is culture?", "what is communication?" and "what is intercultural communication?" the teacher is supposed to stay clear to the answers in mind and in words, because these are the guide light of this field of study. Culture is something lucid when we just keep this idea in mind, but when we talk and discuss about it, it becomes something very obscure. Culture is like an iceberg, small part of which is visible and most part of which are invisible yet powerful and fundamental. Culture is like the water a fish swims in and the grammar of our behavior, based on which scholars of different fields define culture from their own perspectives. American scholars Daniel Bates and Fred Plog propose a descriptive definition which reflects the role of communication: "Culture is a system of shared beliefs, values, customs, behaviors, and artifacts that the members of a society use to cope with their world and with one another, and that are transmitted from generation to generation through learning." The relevant cultural issues and its relations to communication especially intercultural communication should be explored by the teachers to the exact points of cultural differences and effects on communication, cultural similarities and differences between ethic groups and cultures, intercultural contacts and contexts, specific cultural patterns and effects on intercultural communication, culture shock and cultural adaptation, subjective cultural theory, ethic groups, subcultures and racial groups, non-verbal communication, and improving intercultural competence. With these concept and theory of cross-cultural interaction, the teacher can be well equipped to introduce and instruct actual knowledge to their students. In addition to the theoretic concept, understanding the similarities and differences between different cultures in humanism, history, customs and conventions...etc and the roots for these differences, as the main concern of the students, are crucial for a teacher to maintain the expected number of audience in the class.

\section{A global mentality}

With the development of the intellectual environment and the society at large, many scholars at home and abroad probe into the ways of improving intercultural communication teaching content and its ways. Instead of using the traditional way of introducing the basic ideas, concepts and measures of intercultural communication, nowadays scholars in this field tend to foster a specified cultural identity, reflection and tolerance toward diverse cultural interactions as the core of intercultural communication teaching, even though the former way is of great help for students to know the different cultural rules and the relevant linguistic phenomenon. This new trend calls for that the teachers of the courses should have a global mentality, that is to say, certain capacity to understand and appreciate other peoples' cultures, beliefs, hopes, ambitions and history at an international level is the first necessity.

A global mentality is the combination of intercultural thinking and intercultural awareness. Intercultural thinking pattern includes the ability to observe, compare, analyze and conclude the cultural phenomenon during the interaction process. The ability can be categorized into two branches; one is the ability to know and understand a different culture, with which one can understand and appreciate the differences in their communicative behaviors between people with 
different cultural backgrounds and to discover the roots for these dissimilarities; and the other is the ability to analyze the varieties of means and outcomes of intercultural communication, which needs one to compare and conclude the similarities and differences in the history, custom, social development, humanism, language...etc between the native culture and the target culture. (Yang, 16)

While intercultural awareness is thought as kind of perception about oneself, native culture and target culture, the three of which are distinct yet interactive. As for the perception about oneself, it refers to the self-awareness about one's characteristics, capacity and worldviews which define one's attitudes towards intercultural interaction, the degree to which one is willing to present himself/herself, and the ability to control oneself to a favorable outcome. A teacher's personality, attitude, and one's self awareness must be measured to exploit the frontiers of intercultural communication courses, since they are critical to building such amiable environment in class for students as are helpful to identify and control one's thoughts and behaviors to realize the target of communication. The perception about one's cultural identity accumulated by the knowledge and understanding of one's native culture and the target culture is a vital factor that can help to abandon ethnocentrism and diminish prejudice centered cultural relativism for one consensus that there are only differences in culture with no predetermined judgment of good or bad.

Standing at the mountain of the world, expanding mind to the limitless "village", both the teacher and the intercultural communication course itself are supposed to cherish these global mentality and to guide the study of this field towards the top of its development.

\section{Identity}

The research on identity has got a great many achievements, while the one from the perspective of intercultural communication is still growing. Some scholars pose that cross-cultural communication is a process of identity negotiation, in which one keeps sensitive to each other's identity, takes relevant measures, and constantly adapts oneself to other's identity, so that intercultural interaction can be conducted successfully. It is clear that with the development of the intellectual environment identity research and discussion should not be missed out of the intercultural communication courses. Identity includes cultural identity, relational identity and personal identity. Cultural identity could cover all the aspects from one's nationality, nation, region, sex, age, profession, to political tendency or sexual orientation; relational identity refers to the relationships between father and son/daughter, mother and son/daughter, husband and wife, etc; personal identity covers one's personalities and characteristics distinct from others'. Only when the identity is fully understood and clarified can the meaning of cross-cultural communication be demonstrated.

In addition to the discussion of the issue of identity, the intercultural communication is suggested to be explained in terms of political and economical power, which leads to the development of the discussions on language and social identity, intercultural relation in the media, and assimilation and pluralism in the scheme of the courses. As the society and intellectual world develop the corresponding courses have been changed and promoted accordingly, and now the orientation of intercultural communication teaching has transferred from the tradition introduction of basic differences among diverse cultures and the roots for those differences to the emphasize on the discussion of identity awareness. A teaching outline of a course named The Dialogue of diversity: deciphering the cues and codes of intercultural communication offered by University of California Berkeley can demonstrate this trend. The following are included:

Introduction

Basics of intercultural communication

Basics of intercultural communication: verbal and nonverbal codes

Cultural identity development

Influences on priority of cultural identity

Diversity of worldviews

Differences in use of power, leadership

Simulation of values and beliefs influence on use of personal power 
Compa teachers with new tasks and new opportunities to explore new areas of study and broaden their minds. In the process of cross-cultural communication teaching, teacher plays a crucial and decisive role. The teacher himself or herself should be an fluent intercultural communicator with specialized knowledge and skills, including fluent usage of world language or target language, understanding the basic concept and theory of intercultural communication, cherishing a global mentality and clarifying their specific cultural identity and cultural adaptation stage, among which the latter two points deserve great amount of attention and efforts because of the development of academic study and society at large.

\section{Students' need}

This new era of changes and innovations challenges a new framework for students to capture different needs required to become intercultural competent. Now many investigation and research have suggested that students subjecting in the course of intercultural communication begin to lose interest and passion in the study and have little competence in cross-cultural communication mainly because of the traditional method of teacher-orientated teaching, and that a student has even though learned to be competent within a particular cultural setting, he or she is not able to transfer that knowledge and use it appropriately in another cultural setting. To describe the competency required of an international student in our current globalization arena, we can refer to the statement of Phatak: "And if he is going to measure up to the demands of living and working in a foreign country he should also have a feeling for culture; his moral judgments should not be too rigid; he should be able to merge with the local environment with chameleon-like ease and he should show so signs of prejudice" (Phatak, as cited in Forster \& Johnson, 1996, 179-180). It is clear to see that increasing influence of phenomena of cultural diversity in the world required both the teachers and students to have a greater understanding, sensitivity and competence for this issue. The developing trend to globalization create strengthened cultural concerns, leading most professionals to prefer the graduates with multicultural competence; furthermore, varieties of progresses in the field of modern information and communication technology, increasing multinational cooperations and students becoming world travelers have influenced the need for higher levels of cultural competence of students. How to plan the content of the courses on the basis of satisfying students' need of improving their intercultural communication competence is fundamentally critical.

Reflecting on the past teaching experience with the main focus on introducing the fact, concept, knowledge and skills of cultures to students, we may find it easy to see students are restricted to the abstract, obscure and general information on this topic, which is hard for them to digest and can be transferred with many difficulties into practical intercultural communicative ability. Based on the needs of the students, an intercultural communication course should take the circulation of the following steps proposed as procedural culture teaching to attract students' passion and efforts to improve their intercultural communication competence in the level of emotion and behaviors; students are encouraged to: describe the comparison between the native culture and the target culture from their own experiences and the information they have learned in books and put forward hypothesis; verify the hypothesis through doing researching and interviewing with people with different cultural backgrounds; make a diary about the research in order to collect and rebuild materials and information; and conclude and reflect the research on the interactive communication among different cultures across presentation and group discussion. Compared with the traditional information-based and teacher-oriented teaching method, the procedural culture teaching has such advantages as the teaching method has been converted from teacher-centered knowledge inserting 
into student-centered initiative research on the diversity of intercultural phenomenon, the content has been directed from the concern about target culture to the concern about the balance of target culture and native culture, and the goal of the teaching is not only for culture awareness itself but also for the corporate development in emotion and behaviors.

Many scholars abroad (Kramsch, 1993; Byram et al, 2001) propose the idea of procedural culture teaching. They insist that in cross-cultural communication teaching, culture can not be explained in static and fixed factual knowledge but be regarded as changing and developing for students to explore and exploit. Students should be encouraged to study initiatively in the research process, because truly understanding knowledge can not be delivered externally by the teachers and it can only be obtained by students themselves in the understanding and rebuilding the past experience and the practical reality. These student-oriented teaching methods have been proved effective in improving their intercultural communication competence (Byram et al, 2001).

\section{Conclusion}

Teaching intercultural communication course in China is a great challenge for teachers concerned considering the course's goal, content and the relevant methods. Aiming at improving students' intercultural communication competence, the author attempts to make relevant suggestions on the content of the course from the perspective of the teacher's role and the students' needs. A further finding in this paper for the teacher of this course is that he or she should pay more attention and efforts to the presentation of a global mentality and the clarified awareness of their specific cultural identity, in addition to the specialized knowledge and skills, including fluent usage of world language or target language, understanding the basic concept and theory of intercultural communication, cherishing and clarifying their specific cultural identity and cultural adaptation stage, due to the development of academic study and society at large. Another significant aspect of this paper is to remind both teachers and scholars of the students' centered position in the study of the course, and that student is an actual part of this globalized society. The course should climate a situation to foster students' initiatives and creativity in experiencing, discovering, researching and adapting the practical intercultural differences and improve their inter-cultural communication competency not only in the command of knowledge and skills but also in the control of emotions and behaviors. Based on this point, the course book edited by Liao Huaying and published by Beijing Institute of Technology Press in 2010 would be a good reference for students. In this book, a large number of cases of intercultural communication are presented, which provide various raw materials for them to find the roots of the cultural differences and help readers foster a habit of generalizing ideas from the individual facts.

\section{Reference}

[1]. Behmd,V \& Porzelt, S. Intercultural competence and training outcomes of students with experiences abroad [J]. International Journal of Intercultural Relations, 2012, (36):213-223.

[2]. Byram, M., A. Nichols \& D. Stevens. Developing Intercultural Competence in Practice [M]. Clevedon: Multi-lingual Matters, 2001.

[3]. Dubin, F \& E. Olshtain. Course Design [M]. Shanghai: Shanghai Foreign Language Education Press,2002.

[4]. Hans Ruediger Kaufmann, Maria Englezou, \& Ana Garcia-Gallego. Tailoring Cross-Cultural Competence Training [J] Thunderbird International Business Review, 2014, 56(1): 27-40.

[5]. Holmes P \& O Neill G. Developing and evaluating intercultural competence: Ethnographies of intercultural encounters [J]. International Journal of Intercultural Relations, 2012, (36): 707-718 